Article

\title{
How Does Integrated Reporting Change in Light of COVID-19? A Revisiting of the Content of the Integrated Reports
}

\author{
Isabel-María García-Sánchez ${ }^{1}$, Nicola Raimo ${ }^{2, * \mathbb{C}}$, Arcangelo Marrone ${ }^{2}$ and Filippo Vitolla ${ }^{2}$ \\ 1 Instituto Multidisciplinar de Empresa-IME, Campus Miguel de Unamuno, Universidad de Salamanca, \\ 37008 Salamanca, Spain; lajefa@usal.es \\ 2 Department of Economics and Management, LUM Jean Monnet University, 70010 Casamassima (Bari), Italy; \\ marrone@lum.it (A.M.); vitolla@lum.it (F.V.) \\ * Correspondence: raimo.phdstudent@lum.it
}

Received: 30 July 2020; Accepted: 9 September 2020; Published: 15 September 2020

check for updates

\begin{abstract}
The crisis connected to the spread of the COVID-19 pandemic represents an epochal event destined to generate strong economic and social consequences. The impact of the pandemic on business activities and business models also entails rethinking reporting practices. The pandemic has, in fact, created an enormous need for investors and stakeholders in general for future-oriented information relating to the impacts of this event on organizations. Integrated reporting is an ideal tool to provide information related to the effects of the pandemic and provide a holistic view of the future prospects of organizations. This study, using legitimacy theory and based on a two-step methodology, highlighted a series of information that companies will need to have to include in integrated reports to maintain and defend legitimacy. The results provide a double perspective: the first based on content elements and the second based on capitals. The results represent an important guideline for companies for the preparation of future integrated reports.
\end{abstract}

Keywords: integrated reporting; disclosure; COVID-19; legitimacy theory

\section{Introduction}

The global spread of COVID-19 represents the largest health emergency of the last century. It has caused death, human suffering, social isolation, closure of economic activities, and important costs for world states. So, in addition to the heavy balance of human lives and the impact on everyday life, the pandemic brings with it far-reaching economic damage, the first consequences of which are beginning to be felt. Faced with the challenges and risks on the horizon, companies are rightly worried about the repercussions on their employees and their business in the immediate future as well as for the impacts in the near future. In fact, the pandemic has distorted the organizations' business models and has substantially changed the value creation processes. In this regard, just think of the companies operating in the airline sector who will have to rethink their business models in a global way by trying to improve people's propensity to travel and by providing precautions for the protection of passengers. Furthermore, the spread of COVID-19 may not be an isolated event and other similar health emergencies for the future are not excluded. In this regard, in fact, Bill Gates, founder of the Bill \& Melinda Gates Foundation, which promotes educational and health projects, said, "[W]e'll have to prepare for the next one, that I'll say will get attention this time". A similar thought was also expressed by Tedros Adhanom Ghebreyesus, director-general of the World Health Organization who declared, "As we work on responding to this pandemic, we must also work harder to prepare for the next one".

The strong impacts of the pandemic on business models require a rethinking of reporting practices. In light of this catastrophic event, in fact, the mere financial information does not allow one to adequately 
grasp all the impacts of COVID-19 on organizations and on corporate management. Therefore, to date, there is a significant and unprecedented need for future-oriented information that allows for a more holistic view of the impact of external influences, linked to the pandemic, on organizations. In other words, in the light of the events of the past few months, organizations are called upon to provide transparent communication on how COVID-19 is affecting business in order to obtain legitimacy [1]. In addition, they are called to provide complete information to avoid the spread of unofficial news that could prove harmful for the management of the crisis itself and for the perception of the company response outside. This information will have to cover a wide range of issues such as risk management, internal control mechanisms, workplace safety, relations with the natural environment, and business continuity. In this regard, it should be emphasized that taking into account the exceptional nature of the pandemic as well as the magnitude of the foreseeable financial impacts, also the possible non-impact of COVID-19 or even a positive impact (some sectors such as large-scale distribution or telephone companies seem to benefit from the current emergency situation) on the firm performance, represent information that must be communicated to the public.

In light of this, integrated reporting (IR), developed by the International Integrated Reporting Council (IIRC), thanks to its ability to provide a holistic view of business management and a correct representation of value creation processes [2], could be used as the main tool for communication by organizations. It fits into the current context characterized by a growing demand for financial and non-financial information [3-6] from investors, regulatory bodies, and, albeit indirectly, other stakeholders. IR aims to promote a more cohesive and efficient approach to corporate reporting and to "enhance accountability and stewardship for the broad base of capitals (financial, manufactured, intellectual, human, social and relationship, and natural) and promote understanding of their interdependencies" [2] (p. 2). The ability of IR to provide a holistic view of business management is derived mainly from the introduction by the IIRC of eight content elements (organizational overview and external environment, governance, business model, risks and opportunities, strategy and resource allocation, performance, outlook, basis of preparation and presentation) and two fundamental elements (capitals and value creation process) to be included in the integrated reports [7-10].

In this scenario, free from the constraints related to mandatory reporting, characteristic of the financial statements, IR could be used as a tool to describe the implications of COVID-19 on corporate management, thanks to its flexible approach. IR could, therefore, allow one to show the recipients of the information, in a succinct way, the impacts of COVID-19 on the entire business model and on the different areas of business management. In this perspective, a high amount of information within the integrated reports related to the impacts and management of the pandemic could, therefore, represent a solution for companies to obtain legitimacy in this turbulent scenario.

This work aims to identify, through a two-step methodology based on an in-depth analysis of the consequences of COVID-19, the new information needs of investors, the details of the $<$ IR $>$ framework and several integrated reports, and the information that companies will have to insert in their integrated reports, in order to provide a holistic view of the impacts and the management of COVID-19 and obtain legitimacy from investors and stakeholders in general. In this perspective, therefore, this work aims to represent a guide for managers for the preparation of future integrated reports. In fact, it is clear that the management and impacts of COVID-19 will represent a material issue for companies and stakeholders. Companies will, therefore, be required to provide information on the management and effects of the pandemic. Accordingly, this work aims to identify in detail the information relating to the pandemic that companies will have to disclose in the future via integrated reports.

To this end, it is presented in the following structure: Section 2 presents the theoretical background; Section 3 introduces the research methodology; Section 4 presents and discusses the results; and, finally, Section 5 draws conclusions. 


\section{Theoretical Background}

According to legitimacy theory, a company exists and survives if the stakeholders perceive it as a legitimate subject since it complies with social values, norms, and expectations deriving from a sort of implicit social contract [1,11-13]. If a company intends to violate this contract, it is subsequently forced to remedy it, disclosing additional information to the market [11]. Legitimacy can be defined as "a generalized perception or assumption that the actions of an entity are desirable, proper, or appropriate within some socially constructed system of norms, values, beliefs, and definitions" [14] (p. 574). It represents a necessary element to attract resources and obtain the consent of the stakeholders necessary for the survival of the company in the long term.

Legitimacy can be divided into institutional legitimacy and organizational legitimacy. The latter is conceived as the activity aimed at ensuring the market the perfect symmetry between social values and company strategies and respect for the rules of behavior accepted in the social context of which the company is part.

In this regard, corporate transparency and the disclosure of financial and non-financial information $[15,16]$ represent elements capable of managing organizational legitimacy as a constant and continuous process over time. In fact, companies can provide information to justify the activities undertaken and to comply with the social standards imposed by the context. Companies, in essence, can use disclosure as a tool to reduce the pressure imposed by social context.

The presence of legitimacy gaps can question the long-term survival of the company. In this regard, firms can use different strategies to fill a legitimacy gap [17]. The first is represented by the substantive management strategy which provides for an organizational change. This strategy is increasingly effective and allows businesses to change the perceptions of the stakeholders [18], translating into moral legitimacy in the two variants of procedural legitimacy or consequential legitimacy [14]. A second possibility is represented by the symbolic management strategy which consists of representing the company in a manner consistent with expectations and social values [12]. This strategy leads to a dispositional legitimacy [14]. Another stream of the academic literature, on the other hand, illustrates in more detail the following legitimization strategies that companies can adopt: diverting stakeholders' attention from the problem in question, influencing stakeholders' perception of the company's activity, and changing stakeholders' expectations [19]. Firms can combine different legitimization strategies according to the different objectives, which can be to obtain, repair, maintain, or defend legitimacy [20]. These strategies are reflected in the level and quality of voluntary information disclosed by companies.

The addition of information relating to the impacts and management of the COVID-19 pandemic in the integrated reports falls within the perspective of companies to maintain or defend legitimacy. In fact, the pandemic has created an important climate of uncertainty and has significantly increased the need for investors and stakeholders in general to obtain information relating to business management and the effects of the pandemic on business activities. In light of this, companies are asked to provide specific information relating to the pandemic within the integrated reports to maintain or defend legitimacy and avoid the emergence of legitimacy gaps which could call into question the survival of the company in the medium-long term.

\section{Materials and Methods}

In order to identify the information related to the COVID-19 pandemic to be included in the integrated reports, this work involves a two-step methodology.

The first step concerns the identification of the consequences of the COVID-19 pandemic on global economies and business activities and of the new information needs of investors in the light of the spread of the pandemic. Therefore, within this first step, several newspapers, scientific journals in the medical and pharmacological field, and specialized websites were read to identify the consequences of the COVID-19 pandemic on global economies and on the conduct of business. This analysis allowed us to better understand the changes made within the companies and shed light on the new information needs related to the spread of the pandemic. Additionally, in order to obtain a more complete picture 
of the new information needs, several professional investors were interviewed to identify a list of new information that they need in their investment processes. Specifically, professional investors were asked for the information they need for their investment decisions in light of the effects of the COVID-19 pandemic. This was done through semi-structured interviews. This first step allowed us to have a complete overview of the consequences of the COVID-19 pandemic and the information needs of investors.

The second step provides for the detailed analysis of the $<\mathrm{IR}>$ framework provided in 2013 by the IIRC and several integrated reports. Specifically, in relation to the first point, the guiding principles, content elements, and capitals were examined to identify in detail the guidelines and information requests of the $<\mathrm{IR}>$ framework. Furthermore, in relation to the second point, several integrated reports from different organizations were also examined to identify the structures most frequently used and identify the contents generally disclosed by companies. In particular, we focused on integrated reports from healthcare structures and companies that provide risk-related information, considering the important impact of the COVID-19 pandemic on this type of information. Integrated reports were examined to evaluate their structure and content and fully understand the way in which the information connected to the COVID-19 pandemic could be inserted. This second step allowed us to have a complete overview of the $<\mathrm{IR}>$ framework and of the different structures and different contents that companies insert within their integrated reports.

The two-step methodology allowed us to catalogue the new information relating to the COVID-19 pandemic in the different sections and perspectives envisaged by the $<\mathrm{IR}>$ framework based on the guiding principles and to develop a revisiting of the framework in the light of the pandemic event.

\section{Results and Discussion}

\subsection{IR As an Ideal Tool for Information Related to COVID-19 Pandemic}

The $<\mathrm{IR}>$ framework is particularly suitable for providing information about the impacts and management of the pandemic. Preliminarily, it is necessary to remember that the goal of an integrated report is to represent the ability of an organization to create value over time [2]. In this perspective, it becomes fundamental for companies to disseminate information related to the pandemic as a phenomenon that could compromise (or, alternatively, improve) their ability to create value. The suppliers of financial capital to whom the integrated report is mainly addressed appear, therefore, interested in understanding the risks or any opportunities related to pandemic events. The principles-based approach of the $<\mathrm{IR}>$ framework allows a fairly easy way to adapt the standard contents to the specific information related to the pandemic. The principles-based approach, as indicated within the $<\mathrm{IR}>$ framework, allows businesses to achieve a good balance between flexibility and standardization in order to take into account the specific circumstances that characterize pandemic events without compromising the standardization needs of the content that the $<\mathrm{IR}>$ framework pursues. This approach allows comparison with other organizations that present different structural profiles and competitive environments. It should also be noted that the $<\mathrm{IR}>$ framework, by providing for the presence of both quantitative and qualitative information [2], allows a more effective disclosure of the impacts of the pandemic on the ability to create value. In fact, on the one hand, quantitative indicators allow businesses to represent in a concise and more objective way the effects of the pandemic on value creation processes and, on the other, qualitative information deepens and interprets quantitative data and represents the most adequate disclosure approach in all those situations in which the quantitative data ineffectively represent a certain phenomenon (just think of the difficulties of quantitatively representing the changes made to the anti-pandemic protocols and procedures, as well as the representation of the risks and opportunities deriving from the pandemic).

Some guiding principles, discussed below, are therefore the basis of the ability of the $<\mathrm{IR}>$ framework to adapt to the specifics of the context and, in particular, to the peculiarities that characterize pandemic events. 
Strategic focus and future orientation. Although the effects of a pandemic are not always structural, there is no doubt that the significant extent of some exceptional phenomena lead to the rethinking of business models. In this perspective, the strategic focus envisaged in the $<\mathrm{IR}>$ framework must lead organizations to provide detailed information on strategies for adaptation to pandemic events and their ability to create value in the short, medium, and long terms. In more detail, the $<\mathrm{IR}>$ framework is able to highlight the risks and opportunities of the pandemic effects in relation to the company's market position and its business model. The orientation towards the future is the basis of a disclosure that takes into account the relationships between past performance (pre-pandemic) and future performance, highlighting the factors that can change this relationship. In this context, it becomes fundamental to represent those resources and those capitals that are fundamental to achieve the objectives set even in the presence of unfavorable events for the community such as pandemics.

Connectivity of information. An integrated report must make explicit the relationships between the various elements underlying the value creation processes. The connectivity of information concerns primarily the content of the document. In this perspective, pandemic events must be represented in order to reflect the interactions that are created within the system: influence on the resource allocation system (e.g., the greater resources intended for the prevention of infection); adaptation of the strategy to the new risks and new opportunities generated by the pandemic in order to obtain a satisfactory level of performance; and connection of the strategy and business model with the changes generated by pandemic events (e.g., new business units, new markets, new strategic positioning, abandonment of business areas incompatible with the new scenarios related to the pandemic). Second, the integrated report must connect the past, present, and future. In particular, the document must show the managerial actions that explain how past performance can be maintained and improved in the present despite the presence of a pandemic scenario and how, in the future, the level of performance can be made sustainable by implementing a business model that mitigates the risks and seizes the opportunities associated with the new scenario. Third, the integrated report must highlight the connections that are created between the different capitals following the pandemic (e.g., the impact of investments in hardware and software of the IT systems on the anti-pandemic procedures and protocols included in intellectual capital; the impact of the purchase and use of individual protection devices on the environmental performance associated with their disposal).

Stakeholder relationships. In order to represent the ability to create value, it is essential to understand the quality of relations with stakeholders. The stakeholders are in fact the subjects who provide the necessary resources to carry out the business. Consequently, the consent and satisfaction of the stakeholders are fundamental for the success of the company. An integrated report must, therefore, be able to represent the most important aspects that characterize the pandemic scenario and, in particular, the risks and opportunities with respect to each category of stakeholder (e.g., risk of contagion for workers, risks of falling share prices for shareholders, opportunities for developing new business for shareholders, opportunities for consolidating relations with research bodies).

Materiality. An integrated report must provide information on the most significant aspects that affect the ability to create value. The analysis of the materiality of the pandemic scenario allows one to identify the relevant aspects of the pandemic that must be included in the integrated report (e.g., health and safety in the workplace, customer health and safety). Furthermore, it allows one to evaluate the importance of the relevant aspects in relation to the effects on the ability to create value (e.g., the relevance of the pandemic effects on the customers of an air transport company will be different from the relevance of the pandemic effects on the customers of a steel company).

\subsection{A Rethinking of the Content Elements Identified by the $<I R>$ Framework}

A first analysis perspective is represented by the eight content elements introduced by the $<\mathrm{IR}>$ framework. Table 1 summarizes the main aspects that firms need to include in the integrated report in order to maintain or defend their legitimacy and allow investors to make better investment decisions through the analysis of appropriate information and data. These aspects emerged in light of the 
content of the integrated reports analyzed and of the interviews conducted with venture capitalists and business angels that highlighted the information needs related to the pandemic that covered a series of elements ranging from governance to risks, strategies, business models, opportunities, performance, and future prospects of companies.

Table 1. Revisiting integrated reporting (IR) content elements following the pandemic.

\begin{tabular}{l} 
CONTENT ELEMENTS \\
\hline ORGANIZATIONAL OVERVIEW AND EXTERNAL ENVIRONMENT \\
1. Information on the public health and pandemic contrast values \\
2. Information on the presence at operational level of personnel with anti-pandemic skills \\
3. Information on the presence at operational level of anti-pandemic operating structures \\
4. Information on the impact of the pandemic on the activities carried out and the markets served \\
5. Information on the modification of the five competitive forces following the pandemic \\
6. Information on changes in the legal and social context following the pandemic
\end{tabular}

GOVERNANCE

1. Information on the possible presence in the governance structure of members with anti-pandemic skills (e.g., medical doctors, health managers)

2. Information on the possible introduction of specific pandemic governance bodies (e.g., Epidemic Monitoring Committee)

3. Information on any changes undergone by tools, mechanisms, and governance bodies following the pandemic (e.g., control by the audit committee or board on the risks associated with the pandemic)

4. Information on any changes to the compensation plans and dividend distribution following the pandemic

\section{BUSINESS MODEL}

1. Information on the impact of the pandemic on business model inputs (e.g., investments in changes to the structure to allow social distancing, investments in individual protection devices)

2. Information on the impact of the pandemic on the value chain activities (e.g., cleaning and sanitizing of work spaces, smart working, customer reception and assistance, employees' health monitoring; e-commerce)

3. Information on the impact of the pandemic on the outputs of the business model (e.g., state of sanitation of work environments, individual protection devices waste)

4. Information on the impact of the pandemic on the financial outcomes of the business model (e.g., profitability, leverage)

5. Information on the impact of the pandemic on the non-financial outcomes of the business model (e.g., worker health, customer safety)

6. Information on the impact of the pandemic on strategic business units

RISK AND OPPORTUNITIES

1. Information on the health risks associated with the pandemic (e.g., the risk of spread to workers, customers, and suppliers)

2. Information on the financial risks associated with the pandemic (e.g., liquidity risks)

3. Information on the operational risks associated with the pandemic (e.g., risk of loss related to the possible lockdown)

4. Information on the strategic risks associated with the pandemic (e.g., reputational risk associated with pandemic management)

5. Information on the compliance risks associated with the pandemic (e.g., risk of non-compliance with anti-pandemic regulations by workers and customers)

6. Information on any competitive opportunities deriving from the changed context (e.g., new business areas; new markets, new configuration of the value chain)

STRATEGY AND RESOURCE ALLOCATION

1. Information on any changes to the competitive and corporate portfolio strategies following the pandemic (e.g.,

changes in the value proposition, customer targets, entry into new businesses, abandonment of current businesses)

2. Information on any changes to the set of resources and skills managed following the pandemic

PERFORMANCE

1. Information on the specific impact of the pandemic on financial performance

2. Information on the specific impact of the pandemic on environmental performance

3. Information on the specific impact of the pandemic on social performance

OUTLOOK

1. Information on the organization's action plans to face the pandemic

2. Information on future prospects following the pandemic

BASIS OF PREPARATION AND PRESENTATION

1. Analysis of pandemic prevention and public health in the materiality matrix 
Organizational overview and external environment. With regard to the general information concerning organization and external environment, an integrated report should contain information on the value of public health and the fight against the pandemic. In addition, it should contain information about the existence of an internal system of prevention and action against the pandemic (at both personnel and structure level). In addition, an integrated report should include information about the impact of the pandemic on the activities carried out, on the markets served, and on any changes to the five competitive forces. Finally, it should contain information on changes in the legal and social contexts following the pandemic.

Governance. In relation to the governance, an integrated report should present detailed information that would allow users to assess the effectiveness of the specific structure created to deal with the contagion within the company, the presence of different anti-pandemic specialists, and any changes in policies and responsibilities that have been made as a result of the pandemic.

Business model. In relation to the business model, companies should first provide information relating to the necessary investments that have been made to contain the contagion and relating to the impact that the pandemic has had on the results achieved by the company and the changes that have been necessary to make in the corporate strategy. In addition, firms should provide information about the environmental implications of the means of protection and the social consequences of the pandemic for the different groups, mainly suppliers, employees, and customers.

Risk and opportunities. In relation to risks, companies should provide information regarding possible operational and strategic risks, as well as compliance, without forgetting the negative externalities that may occur at the labor, commercial, and financial level. Furthermore, in relation to the opportunities, companies should include within the integrated report information necessary for the users to know the business strengths and opportunities arising from the pandemic.

Strategy and resource allocation. In relation to the strategy and resource allocation, companies should provide information relating to changes undergone by competitive and corporate portfolio strategies following the spread of the pandemic and information relating to any changes to the set of resources and skills managed by the company due to the new pandemic scenario.

Performance. In relation to performance, companies should provide information about the impacts of the pandemic, focusing attention not only on financial performance, but also on environmental and social performance.

Outlook. In this section, companies should include information about plans and actions put in place to face the pandemic and information about future prospects following the pandemic.

Basis of preparation and presentation. In relation to this specific element, companies should include the analysis of pandemic prevention and public health within the materiality matrix.

\subsection{A Focus on the Capitals Identified by the $<I R>$ Framework}

A second analysis perspective is represented by the focus on capitals, which represent fundamental disclosure elements, introduced by the $<\mathrm{IR}>$ framework. Capitals can provide a more effective representation of content elements. Compared to the representation of content elements, capitals can be treated as inputs and outcomes. In this regard, the pandemic has effects both on capital intended as inputs and on capital understood as outcomes. Interviews conducted with venture capitalists and business angels showed the goodness of a capitals-based analysis perspective, which emerged as a solution capable of offering a complete and more direct overview of the consequences of the pandemic on business management. Table 2 summarizes the main aspects regarding the capitals that firms need to include in the integrated report. 
Table 2. Revisiting IR capitals following the pandemic.

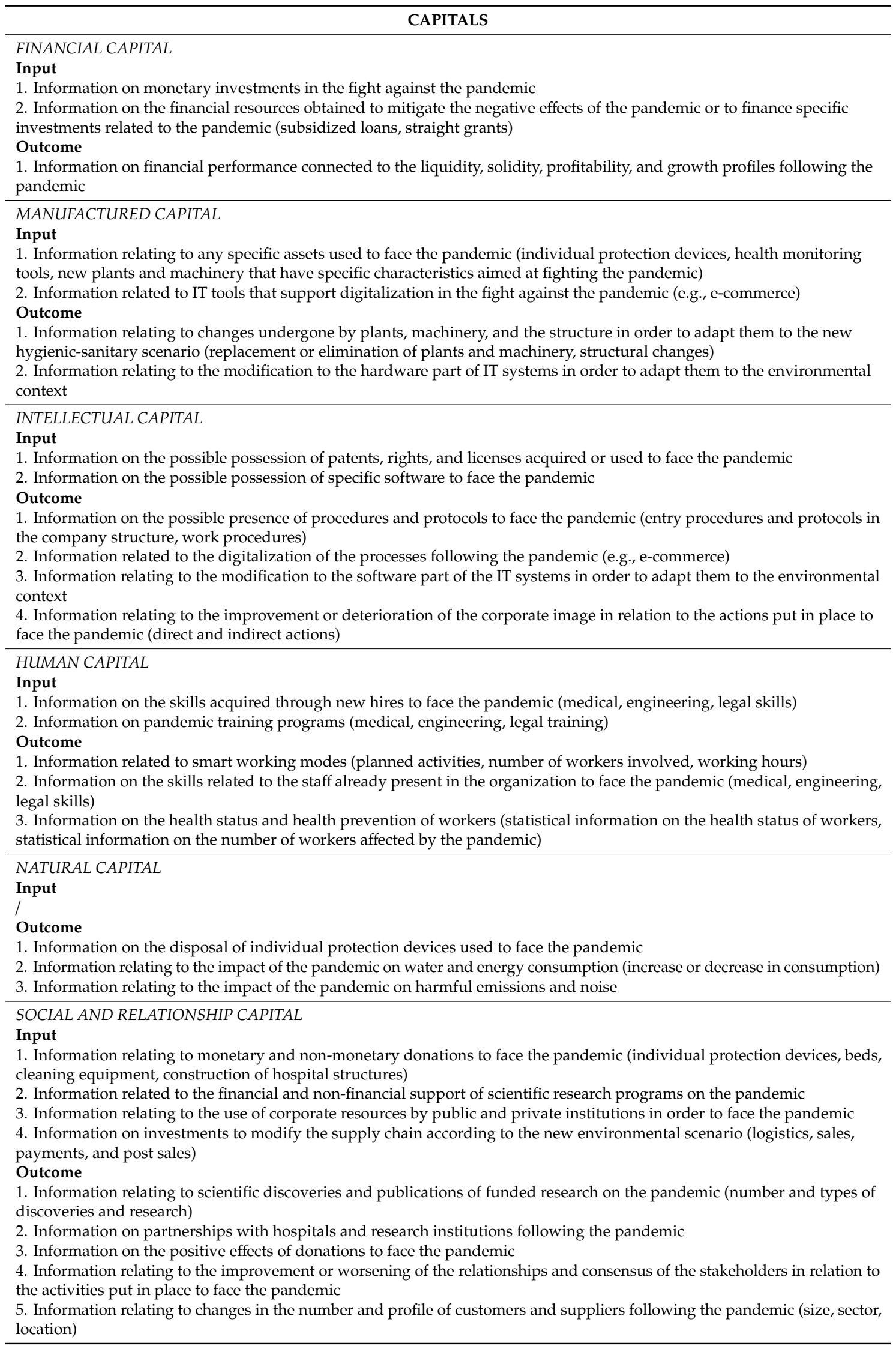


Financial capital. With regard to financial capital intended as input, companies should include in the integrated report information related to monetary investments incurred to face the pandemic and information related to any monetary resources obtained from third parties such as governments to finance-specific investments related to the fight against the pandemic. Furthermore, as regards financial capital intended as an outcome, companies should include information related to the impact of the pandemic on the liquidity, solidity, profitability, and growth profiles.

Manufactured capital. With regard to manufactured capital intended as input, firms should provide information about the material assets used to face the pandemic. Furthermore, as regards manufactured capital intended as an outcome, companies should indicate all modifications and adaptations undergone by the structure, such as replacement or elimination of plants and machinery, to adapt it to the new hygienic-sanitary scenario.

Intellectual capital. With regard to intellectual capital intended as input, firms should provide information about patents, rights, licenses, and specific software acquired or used to face the pandemic. Furthermore, as regards intellectual capital intended as an outcome, companies within the integrated report should indicate the possible presence of protocols and procedures and innovations, in terms of digitalization, to face the pandemic. Finally, companies must provide information about the improvement or deterioration of the corporate image in relation to the actions and plans implemented to deal with the pandemic.

Human capital. With regard to human capital intended as input, companies should include within the integrated reports information about the skills acquired through new hires to face the pandemic and information about the pandemic training programs. In addition, as regards human capital intended as an outcome, companies should provide information about smart working methods, workers' health status, prevention methods, and skills of workers already present in the company to face the pandemic.

Natural capital. With regard to natural capital intended as outcome, companies should provide information on the effects of pandemic management on the environment, with reference to water and energy consumption, the disposal of individual protection devices, emissions, and noise.

Social and relationship capital. With regard to social and relationship capital intended as input, companies should provide information on support to society (in monetary and non-monetary terms) and to the scientific community. Furthermore, as regards social and relationship capital intended as an outcome, companies should inform users about partnerships with hospitals and research institutions, the effects of donations made, changes in the number and profile of customers and suppliers, and the improvement or the worsening of relationships with stakeholders following the pandemic.

\section{Conclusions}

COVID-19, in addition to negative health externalities, carried out significant real risks and losses for society and business, requiring decision-making to alleviate problems of immediate liquidity, layoffs, loss of contracts and clients, etc. In this sense, it seems necessary for companies to incorporate in their corporate reports information that allows owners, investors, employees, and any other user to know the immediate actions they have put in place to manage and mitigate the negative externalities arising from this pandemic. Future risks involving the company, as well as business opportunities that may arise from the new global landscape, must also be involved.

In this sense, IR, thanks to its flexible approach and its ability to provide a holistic picture of business management [21-27], seems to be the most appropriate tool to represent business-level consequences of the pandemic. This study aimed to identify the information that companies will have to add to the integrated reports following the COVID-19 pandemic. The results show a series of information, in a double perspective based first on the general content elements and then on the specific capitals identified by the $<\mathrm{IR}>$ framework, which companies will have to include in their integrated reports in order to maintain and defend legitimacy and allow investors more accurate investment processes. This information mainly relates to the existence and effectiveness of the internal pandemic prevention and action system; the integration of the risks and opportunities that this pandemic 
implies from a competitive point of view in the company's strategy; and financial and non-financial consequences of the epidemic on global performance, profitability, liquidity, solvency, investment policy, contracting, and training of human capital.

This study extends the scope of legitimacy theory in the disclosure field, showing how the inclusion of information related to the effects and management of the pandemic can be a means of maintaining and defending legitimacy and avoiding legitimacy gaps. In fact, if a company is accepted as a good corporate citizen, the public will have certain expectations in relation to the information dissemination. In this perspective, the disclosure of information related to the effects and management of the pandemic represents a solution for companies to meet the expectations of users and keep intact their image and legitimacy. Furthermore, it provides a guideline for companies for the preparation of future integrated reports by offering a list of elements that will have to take into account in the process of drafting documents.

This work is not without limitations. In fact, although the approach taken is intended to be comprehensive with respect to the information to be incorporated, this study does not take into account the sectorial and dimensional specificities of companies. This work offers several ideas for future studies. In fact, future research, starting from this study, could develop a "COVID-19 disclosure index" in order to provide evidence of the level of applications of our proposal and investigate the determinants of the level of information related to the pandemic disclosed by companies.

Author Contributions: Conceptualization, I.-M.G.-S., N.R., A.M., and F.V.; methodology, N.R.; validation, I.-M.G.-S., N.R., A.M., and F.V.; investigation, N.R.; resources, A.M.; data curation, I.-M.G.-S; writing-original draft preparation, I.-M.G.-S., N.R., A.M., and F.V.; writing-review and editing, N.R. and A.M.; visualization, I.-M.G.-S., and F.V.; supervision, I.-M.G.S., and F.V.; project administration, I.-M.G.-S., and F.V. All authors have read and agreed to the published version of the manuscript.

Funding: This research received no external funding

Conflicts of Interest: The authors declare no conflict of interest.

\section{References}

1. Dowling, J.; Pfeffer, J. Organizational Legitimacy: Social Values and Organizational Behavior. Pac. Sociol. Rev. 1975, 18, 122-136. [CrossRef]

2. IIRC. International Framework. 2013. Available online: http://integratedreporting.org/resource/internationalir-framework (accessed on 1 June 2020).

3. Du Toit, E.; Van Zyl, R.; Schütte, G. Integrated reporting by South African companies: A case study. Meditari Acc. Res. 2017, 25, 654-674. [CrossRef]

4. Vitolla, F.; Raimo, N.; Rubino, M.; Garzoni, A. How pressure from stakeholders affects integrated reporting quality. Corp. Soc. Responsib. Environ. Manag. 2019, 26, 1591-1606. [CrossRef]

5. Raimo, N.; Vitolla, F.; Marrone, A.; Rubino, M. The role of ownership structure in integrated reporting policies. Bus. Strat. Environ. 2020, 29, 2238-2250. [CrossRef]

6. Vitolla, F.; Raimo, N.; Rubino, M. Board characteristics and integrated reporting quality: An agency theory perspective. Corp. Soc. Responsib. Environ. Manag. 2019, 27, 1152-1163. [CrossRef]

7. Pistoni, A.; Songini, L.; Bavagnoli, F. Integrated Reporting Quality: An Empirical Analysis. Corp. Soc. Responsib. Environ. Manag. 2018, 25, 489-507. [CrossRef]

8. Vitolla, F.; Raimo, N.; Rubino, M. Appreciations, criticisms, determinants, and effects of integrated reporting: A systematic literature review. Corp. Soc. Responsib. Environ. Manag. 2019, 26, 518-528. [CrossRef]

9. Marrone, A.; Oliva, L. Measuring the Level of Integrated Reporting Alignment with the Framework. Int. J. Bus. Manag. 2019, 14, 110. [CrossRef]

10. Vitolla, F.; Raimo, N. Adoption of Integrated Reporting: Reasons and Benefits-A Case Study Analysis. Int. J. Bus. Manag. 2018, 13, 244. [CrossRef]

11. Shocker, A.D.; Sethi, S.P. An Approach to Incorporating Societal Preferences in Developing Corporate Action Strategies. Calif. Manag. Rev. 1973, 15, 97-105. [CrossRef]

12. Ashforth, B.E.; Gibbs, B.W. The Double-Edge of Organizational Legitimation. Organ. Sci. 1990, 1, $177-194$. [CrossRef] 
13. Deegan, C. The legitimising effect of social and environmental disclosures-A theoretical foundation. Account. Audit. Account. J. 2002, 15, 282-311. [CrossRef]

14. Suchman, M.C. Managing legitimacy: Strategic and institutional approaches. Acad. Manag. Rev. 1995, 20, 571-610. [CrossRef]

15. Guthrie, J.; Parker, L.D. Corporate social disclosure practice: A comparative international analysis. Adv. Public Interest Account. 1990, 3, 159-175.

16. Chu, C.I.; Chatterjee, B.; Brown, A.M. The current status of greenhouse gas reporting by Chinese companies. Manag. Audit. J. 2012, 28, 114-139. [CrossRef]

17. Fernando, S.; Lawrence, S. A theoretical framework for CSR practices: Integrating legitimacy theory, stakeholder theory and institutional theory. J. Theor. Account. Res. 2014, 10, 149-178.

18. Kim, J.-N.; Bach, S.B.; Clelland, I.J. Symbolic or Behavioral Management? Corporate Reputation in High-Emission Industries. Corp. Reput. Rev. 2007, 10, 77-98. [CrossRef]

19. Lindblom, C.K. The implications of organizational legitimacy for corporate social performance and disclosure. In Proceedings of the Critical Perspectives on Accounting Conference, New York, NY, USA, 1994.

20. O'Donovan, G. Environmental disclosures in the annual report. Account. Audit. Account. J. 2002, 15, 344-371. [CrossRef]

21. Vitolla, F.; Raimo, N.; Rubino, M.; Garzoni, A. The impact of national culture on integrated reporting quality. A stakeholder theory approach. Bus. Strat. Environ. 2019, 28, 1558-1571. [CrossRef]

22. Vitolla, F.; Salvi, A.; Raimo, N.; Petruzzella, F.; Rubino, M. The impact on the cost of equity capital in the effects of integrated reporting quality. Bus. Strat. Environ. 2020, 29, 519-529. [CrossRef]

23. Salvi, A.; Vitolla, F.; Giakoumelou, A.; Raimo, N.; Rubino, M. Intellectual capital disclosure in integrated reports: The effect on firm value. Technol. Forecast. Soc. Chang. 2020, 160, 120228. [CrossRef]

24. Vitolla, F.; Raimo, N.; Marrone, A.; Rubino, M. The role of board of directors in intellectual capital disclosure after the advent of integrated reporting. Corp. Soc. Responsib. Environ. Manag. 2020. [CrossRef]

25. Salvi, A.; Vitolla, F.; Raimo, N.; Rubino, M.; Petruzzella, F. Does intellectual capital disclosure affect the cost of equity capital? An empirical analysis in the integrated reporting context. J. Intellect. Cap. 2020. [CrossRef]

26. Vitolla, F.; Raimo, N.; Rubino, M. Gli effetti della cultura nazionale sulla qualità della disclosure del capitale intellettuale nel contesto dell'Integrated Reporting. Manag. Control 2020, 1, 137-160. [CrossRef]

27. Vitolla, F.; Raimo, N.; De Nuccio, E. Integrated reporting: Development and state of art-The Italian case in the international context. Int. J. Bus. Manag. 2018, 13, 233-240. [CrossRef] 